\title{
Advanced Synthesis and 3D-AFM-Structural Features of Mono-Metalized Cyclotetraphosphates
}

\author{
Khaled M. Elsabawy ${ }^{1,2, ~ *, ~ A . ~ E l-M a g h r a b y ~}{ }^{2,3}$ \\ ${ }^{1}$ Materials Science Unit, Chemistry Department, Faculty of Science, Tanta University, Tanta, Egypt \\ ${ }^{2}$ Department of Chemistry, Faculty of Science, Taif University, Taif, Kingdom of Saudi Arabia \\ ${ }^{3}$ Ceramic Department, Physics Department, National Research Center, Dokki, Tahrirst., Egypt \\ Email address: \\ khaledelsabawy@yahoo.com (K. M. Elsabawy),ksabawy@yahoo.com (A. El-Maghraby) \\ ${ }^{*}$ Corresponding author
}

\section{To cite this article:}

Khaled M. Elsabawy, A. El-Maghraby. Advanced Synthesis and 3D-AFM-Structural Features of Mono-Metalized Cyclotetraphosphates. American Journal of Materials Synthesis and Processing. Vol. 2, No. 1, 2017, pp. 5-16. doi: 10.11648/j.ajmsp.20170201.12

Received: March 12, 2017; Accepted: March 29, 2017; Published: April 19, 2017

\begin{abstract}
Solution route applying the precursor of metaldihydrogen phosphate dihydrate was used to synthesize Mcyclophosphatesat ambient temperature (cobalt (II) was selected as model for metal in these investigations). The precursor was fired and sintered at different temperatures $\left(600,800,1000\right.$ and $\left.1100^{\circ} \mathrm{C}\right)$ respectively to optimize best conditions to obtain $\mathrm{Co}_{2} \mathrm{P}_{4} \mathrm{O}_{12}$ crystal form with high purity. The products were monitored by both of XRD, IR spectra by additional to accurate imaging via scanning electron microscope (SEM) and AFM-microscopeto analyzesurface topology and microstructural features of the metal cyclotetraphosphate. Structural investigations via XRD proved that the product obtained at $1100^{\circ} \mathrm{C}$ is the best and fine structure with monoclinic structure phase and $C 12 / C 1$ space group with lattice parameter $a=11.809(2)$, $b=8.293(1), c=9.923$ (2) A respectively. A visualized investigations were performed to confirm structure validity and stability at temperature of sintering $\left(1100^{\circ} \mathrm{C}\right)$. Visualization studies indicated that variations of bond distances between $\mathrm{Co} 1, \mathrm{Co} 2, \mathrm{P} 1$ and $\mathrm{P} 2$ and different six oxygen atoms $(\mathrm{O} 1, \mathrm{O} 2, \mathrm{O} 3, \mathrm{O} 4, \mathrm{O} 5$ and $\mathrm{O} 6)$ inside crystal lattice are responsible for increasing lattice flexibility factor (by controlling in shrinkage and expansion coefficient) and consequently increase its bonds stability to break.
\end{abstract}

Keywords: Synthesis, Ceramics, XRD, IR, SEM, AFM, Visualization

\section{Introduction}

Cyclic phosphates (or cyclophosphates) have a ring anionic unit, and have the general formula $[\mathrm{PnO} 3 \mathrm{n}] \mathrm{n}-$, where $\mathrm{n} \leq 3$. In this geometry each phosphate tetrahedronshares 2 oxygen atoms with its neighbour, giving an $\mathrm{O} / \mathrm{P}$ ratio of $3: 1$. Ultraphosphates, in contrast to polyphosphates and cyclic phosphates, are branched: meaning the anionic unit contains phosphate tetrahedra that share 3 of their oxygen atoms, which can form various different geometries such as threedimensional networks, infinite ribbons and layers, [6] or finite groups.

Ultraphosphates undergo hydrolysis rapidly due to the triply linked tetrahedra and so are somewhat unstable. The general anionic formula for ultraphosphates is $[\mathrm{P}(\mathrm{n}+2) \mathrm{O}(3 \mathrm{n}+5)] \mathrm{n}-[1-3]$.

Morphology influences not only the intrinsic chemical, optical, and catalytic properties of micro-/nanoscalemetal phosphates, but also theirrelevant applications in electronic, biocompartible and biodegradable intissue $[2,4]$.

As one of the members of phosphate material family, transition metal cyclotetraphosphate micro-/nanoparticles can be usedin potential pigments, selective catalysts, phosphors, materials for corrosion-resistant coatings and biocompartible and biodegradable intissue [5-8]. Several divalent including $3 \mathrm{~d}$ metals, namely, $\mathrm{Mn}, \mathrm{Co}, \mathrm{Fe}, \mathrm{Zn}, \mathrm{Cu}$, and $\mathrm{Ni}$, are known to form the singlemetal cyclotetraphosphate $\mathrm{M}_{2} \mathrm{P}_{4} \mathrm{O}_{12}$, where $\mathrm{M}$ (II) stands for a divalent metal. The binary metal cyclotetraphosphates $\mathrm{M}_{2-\mathrm{x}} \mathrm{A}_{\mathrm{x}} \mathrm{P}_{4} \mathrm{O}_{12}$ ( $\mathrm{M}$ and $\mathrm{A}=\mathrm{Mg}, \mathrm{Ca}, \mathrm{Mn}$, $\mathrm{Co}, \mathrm{Ni}, \mathrm{Zn}$, or $\mathrm{Cu} ; \mathrm{x}=0-2)$, isostructural with the single metal cyclotetraphosphates $\mathrm{M}_{2} \mathrm{P}_{4} \mathrm{O}_{12}$, were prepared by Trojan et al. [5-8] and Boonchomet al. [9-11]. All these compounds have similarX-ray diffraction patterns and close unit cell parameters, which crystallize in monoclinic space group $\mathrm{C} 2 / \mathrm{c}$ $(Z=4)$ [12]. Various methods have been employed to synthesize binary metal cyclotetraphosphates, including two- 
step thermal method [5-8], hydrothermal synthesis [5] and the decomposition of binary metal (II) dihydrogenphosphates (M1-yAy $\left(\mathrm{H}_{2} \mathrm{PO}_{4}\right)_{2} \mathrm{nH} 2 \mathrm{O}$; whereMand $\mathrm{A}=\mathrm{Ca}, \mathrm{Mg}, \mathrm{Mn}, \mathrm{Fe}$, $\mathrm{Co}, \mathrm{Ni}, \mathrm{Cu}$ or $\mathrm{Zn} ; \mathrm{y}=0-1 ; \mathrm{n}=1-4)$ [9-11]. This work is of interest because it appears economically advantageous to replace partially the divalent metal cations by some cheaper divalent element which could also improve special properties as above mentioned [1-4]. However, it is relevant to synthesize binary cyclotetraphosphate and its solid solution because changing the metal ratio influences its useful properties. Consequently, it is a major challenge to synthesize binary metal cyclotetraphosphate micro-/nanoparticles with its intrinsic shape-dependent properties and resulting application. Recently, cobalt iron pyrophosphate $\mathrm{CoFeP}_{2} \mathrm{O}_{7}$ and cobalt iron cyclotetraphosphate $\mathrm{CoFeP}_{4} \mathrm{O}_{12}$ were prepared by mixing of $\mathrm{CoCO}_{3}, \mathrm{Fe}$ and $\mathrm{H}_{3} \mathrm{PO}_{4}$ in watermethanol and in water- acetone, respectively [13, 14].

The difference of media (solvents) in the precipitation process leads to the obtaining different phosphates, asrevealed by XRD and FTIR data. Due to its solubility in water and its ability to associate with metal ions inmedia, solvent has been used as a binder cum gel for shaping materials (bulk, porous, micro- or nano-particles) and a matrix for entrapment of ions to generate a gelled precursor which resulted in obtaining different material or same material with different size and morphology after heat treatment. The results obtained are also in agreement with other phosphate group reported in literature $[15,16]$.

The major goal of the present investigations is understanding the role of structural parameters within crystal lattice of $\mathrm{M}_{2} \mathrm{P}_{4} \mathrm{O}_{12}$ that stabilize structure of crystal even at elevated temperatures. Furthermore understanding the structural parameters effects on the morphological and surface nature of metalized cyclotetraphosphates.

\section{Experimental}

\subsection{Synthesis of Metal-Cyclotetraphosphate}

The cobalt cyclotetraphosphate was synthesized via three step reactions $1^{\text {st }}$ reaction is dissolving cobalt carbonate in few drops of concentrated nitric acid forming acidic cobalt nitrate then solution neutralized by conc. ammonia solution. $2^{\text {nd }}$ step is the reaction with $70 \%$ phosphoric acid forming cobalt dihydrogen phosphate at temperature $230^{\circ} \mathrm{C} .3^{\text {rd }}$ step is firing followed by sintering process at $1100^{\circ} \mathrm{C}$ to form violet powder from pure cobaltcyclotetraphosphate. These steps are in patial agreement with [5].

$$
\begin{gathered}
\mathrm{M}^{\mathrm{II}} \mathrm{CO}_{3}+\text { few drops of } \mathrm{HNO}_{3} \rightarrow \mathrm{M}\left(\mathrm{NO}_{3}\right)_{2} \\
\mathrm{M}\left(\mathrm{NO}_{3}\right)_{2}+2 \mathrm{H}_{3} \mathrm{PO}_{4} \stackrel{\Delta 230^{\circ} \mathrm{C}}{\longrightarrow} \mathrm{M}\left(\mathrm{H}_{2} \mathrm{PO}_{4}\right)_{2}+\mathrm{H}_{2} \mathrm{O}+\mathrm{NO}_{2} \\
\mathrm{M}\left(\mathrm{H}_{2} \mathrm{PO}_{4}\right)_{2} \stackrel{\Delta 1100^{\circ} \mathrm{C}}{\longrightarrow} \mathrm{M}_{2} \mathrm{P}_{4} \mathrm{O}_{12}(\text { where } \mathrm{M}=\mathrm{Co})
\end{gathered}
$$

Theviolet powder from pure cobaltcyclotetraphosphate was grounded in agate mortar for $15 \mathrm{~min}$. then the resulted powder forwarded to perform the different structural measurements.

\subsection{Structural Measurements}

The X-ray diffraction (XRD): Measurements were carried out at room temperature on the fine ground samples using $\mathrm{Cu}-\mathrm{K} \alpha$ radiation source, $\mathrm{Ni}$-filter and a computerized STOE diffractometer.

Germany with two theta step scan technique. Rietveld andindexing of structure were made via Fullprof package and Gesasprogram.

A visualized studies of crystal structure were made by using Diamond Molecular Structure version 3.2 package, Germany and MERCURY-2.3 depending up on single crystal structural data of pure cobalt cyclotetraphosphatesincluding atomic coordinates of monoclinic phase supplied from ICSD-Karlsruhe-Germany. Scannig electron microscopy (SEM): measurements were carried out along ab-plane using a small pieces of the prepared samplesby using a computerized SEM camera with elemental analyzer unit Shimadzu (Japan). Atomic force microscopy (AFM): Highresolution Atomic Force microscopy (AFM) is used for testing morphological features and topological map (Veeco-di Innova Model-2009-AFM-USA). The applied mode was tapping non-contacting mode. For accurate mapping of the surface topology AFM-raw data were forwarded to the Origin-Lab version 6-USA program to visualize more accurate three dimension surface of the sample under investigation. This processis new trend to get high resolution 3D-mapped surface for very small area.

A visualization study made is concerned by matching and comparison of experimental and theoretical data of atomic positions, bond distances, oxidation states and bond torsion on the crystal structure formed. Some of these data can be obtained free of charge from The Cambridge Crystallographic Data Centre via www.ccdc.cam.ac.uk/data_request/cif, or by emailing data_request@ecdc.cam.ac.uk, or by contacting ICSD-FizKarlsruhe-Germany.

\subsection{FT-Infrared Spectroscopy}

The infrared spectra of the solid products obtained were recorded from $\mathrm{KBr}$ discs using a Shimadzu FT-IR Spectrophotometer in the range from 400 to $4000 \mathrm{~cm}^{-1}$.

\section{Results and Discussion}

\subsection{Structural Identification}

Figure 1 displays different $\mathrm{x}$-ray diffraction patterns of cobalt cyclotetraphosphate at different

Sintering temperatures $\left(600,800,1000\right.$ and $\left.1100^{\circ} \mathrm{C}\right)$ respectively. The accurate analyses of these patterns were performed by using both of rietveld andindexing via Fullprof package and Gesasprogram. The analysis is focused on the main intense reflection peaks (Fingerprint of structure) and 
indicated that cobalt cyclotetraphosphateis mainly belong to single monoclinic phase with $\mathrm{C} 12 / \mathrm{c} 1$ space group as symbolized by pink cycles in Fig. 1 and only very few percentage of cobalt oxide as secondary phase in minor. It was observed that the impurity phases are decreasing as sintering temperatures are increasing as shown in Fig. 1 where impurity phases are assigned by blue squares. The comparisons of most intense reflections peaks in all patterns (fingerprint reflections represent monoclinic -phase) indicated that cobalt cyclotetraphosphate which is sintered at $1100^{\circ} \mathrm{C}$ is the best fit one with high purity than others which sintered at temperatures 600,800 and $1000^{\circ} \mathrm{C}$ respectively.

In the hypothesis of isostructural, due to existence of cobalt (II) and Cobalt (III) the spectrum peaks for the system of cobalt cyclotetraphosphate (solid solution) which is single metal cyclotetraphosphate $\left(\mathrm{M}_{2} \mathrm{P}_{4} \mathrm{O}_{12}, \mathrm{M}=\mathrm{Co}\right)$ are quite similar because of the equivalent electronic charges and the close radii of cations. Consequently, all the diffraction peaks in the Fig. 1 are found to be in agreement with monoclinic $\mathrm{M}_{2} \mathrm{P}_{4} \mathrm{O}_{12}$ and space group $\mathrm{C} 12 / \mathrm{c} 1$ without violation. Only few characteristic peaks of other impurities (e. g. Co-Oxide) was clearly observed at lower sintering temperatures (600, $\left.800^{\circ} \mathrm{C}\right)$.

From XRD analysis (Figure 1), grain size evaluated and calculated according to the Scherrer's formula: $D=K \lambda /(\beta \cos$ $\theta$ ), where $\mathrm{D}$ is particle diameter, $\mathrm{K}=0.89$ (the Scherrer's constant), $\lambda=1.5406$ (wavelength of the X-ray used), $\beta$ is the width of line at the half-maximum intensity and $\theta$ is the corresponding angle. The average crystallite size of product is estimated from the strongest three diffraction peaks below $40^{\circ}$ for $2 \theta$ and found to be $98 \pm 11 \mathrm{~nm}$. This crystallite size of the prepared cobalt cyclotetraphosphate is smaller than those data estimated from SEM and AFM-investigations in the present work which confirm that the powder mixture of cobalt cyclotetraphosphate is not unified grain sizes and grain sizes are variated in the bulk than surface's layers. The lattice parameters were calculated from the XRD spectra and found to be $a=11.809(2), b=8.293(1), c=9.923(2) \mathrm{A}$, which are very close to those of the standard data file (ICSD \#300027) and the literatures [9-11, 14].

\section{Monoclinic-126-Phase}

- Impurity-Phases

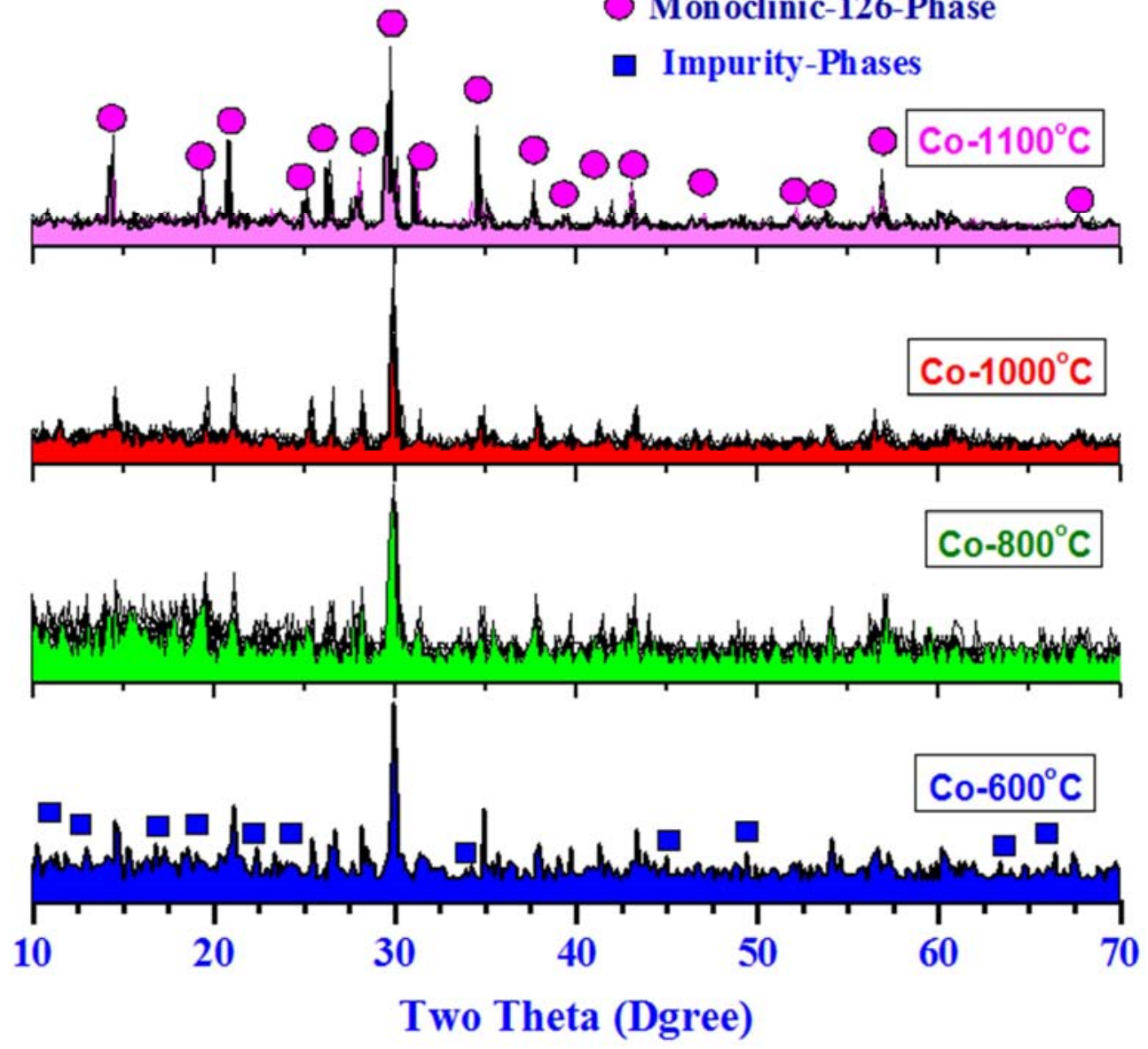

Fig. 1. X-ray diffraction patterns of cobalt cyclotetraphosphate at differentsintering temperatures $\left(600,800,1000\right.$ and $\left.1100^{\circ} \mathrm{C}\right)$ respectively.

\subsection{FT-IR-Spectroscopic Investigations}

Figure 2 displays infrared spectra recorded for $\mathrm{Co}_{2} \mathrm{P}_{4} \mathrm{O}_{12}$ (126-Phase $=\mathrm{AB}_{2} \mathrm{X}_{6}$ structure type) after firing process and sintering at $1100^{\circ} \mathrm{C}$. The most intense reflection pear of IRspectra are assigned by red cycles as clear in Figure 2. It is well known that the $\mathrm{Co}_{2} \mathrm{P}_{4} \mathrm{O}_{12}$ structure is mainly characterized by a three- dimensional framework with $\mathrm{MO}_{6}$ $(\mathrm{M}=\mathrm{Co})$ polyhedral linkedwith $\mathrm{P}_{4} \mathrm{O}_{12}$ ringsby $\mathrm{M}-\mathrm{O}-\mathrm{P}$. The basic structure unit is the centrosymmetriccyclotetraphosphatering $\mathrm{P}_{4} \mathrm{O}_{12}$ and therefore vibrationalmodes can 
consider itas made up of the $\left[\mathrm{P}_{4} \mathrm{O}_{12}\right]^{4-}$ anion. The different vibrational modes of $\left[\mathrm{P}_{4} \mathrm{O}_{12}\right]^{4-}$ ion observed in the frequency range of $370-1400 \mathrm{~cm}^{-1}$ are assignedaccording to the literature [17-19].

The peaks splitting in theseregions is due to the different strength of the bond between cations $\left(\mathrm{M}=\mathrm{Co}^{2+} \mathrm{orCo}^{3+}\right)$ and anion $\left[\mathrm{P}_{4} \mathrm{O}_{12}\right]^{4-}$, which confirm the insertingdifferent cations in the skeletal aswell as the formation of multi-valence cobalt (II, III) cyclotetraphosphate as confirmed in the visualization studies part. The anion contains the $\left[\mathrm{PO}_{2}\right]^{2-}$ radical and the $\mathrm{P}-$ $\mathrm{O}-\mathrm{P}$ bridge which differ in their bond strength and as result multi-splitting processes are occurred as shown in Figure.2. As the $\mathrm{P}-\mathrm{O}$ bondstrength in the $\left[\mathrm{PO}_{2}\right]^{2-}$ radical is stronger than in the $\mathrm{P}-\mathrm{O}-\mathrm{P}$ bridge, thestretching frequencies of the $\left[\mathrm{PO}_{2}\right]^{2-}$ radical are expected to be higher thanthose in the $\mathrm{P}-$ $\mathrm{O}-\mathrm{P}$ bridge. The $\mathrm{P}-\mathrm{O}$ bonds in the $\left[\mathrm{PO}_{2}\right]^{2-}$ radical show itsasymmetric and symmetric stretching frequencies around $1327-1237$ and $1150-1000 \mathrm{~cm}^{-1}$, respectively.
The asymmetric and symmetricstretching frequencies of the $\mathrm{P}-\mathrm{O}-\mathrm{P}$ bridge are observed in the regions of $1000-900$ and $800-700 \mathrm{~cm}^{-1}$, respectively. The symmetric $\mathrm{P}-\mathrm{O}-$ Pbridge stretching modes occur at 736 and $714 \mathrm{~cm}^{-1}$. These observedbands are known to be the most striking feature of cyclotetraphosphatespectra, along with the presence of the vas - OPO- band. From X-raydiffraction data [12], it was shown that the crystal structure ismonoclinic (space group $\mathrm{C} 2 / \mathrm{c} 1)$ with a cyclic structure of the $\left[\mathrm{P}_{4} \mathrm{O}_{12}\right]^{4-}$ anion. This has been confirmed by the IRmeasurements. The bendingmodes are expected in the area $600-400 \mathrm{~cm}^{-1}\left[\mathrm{PO}_{2}\right]^{2-}$ radical) and $400-370 \mathrm{~cm}^{-1}$ (P-O-P bride). Themetal-O stretching usually appears in thebending mode region as the bending modes of the $\mathrm{P}-\mathrm{O}-\mathrm{P}$ bridge andabsorption bands associated with these vibrations are usually veryweak. The weak IR band at 400 $\mathrm{cm}^{-1}$ is probably due to metal-Oxide $\sim(\mathrm{Co}-\mathrm{O})$ stretching mode.

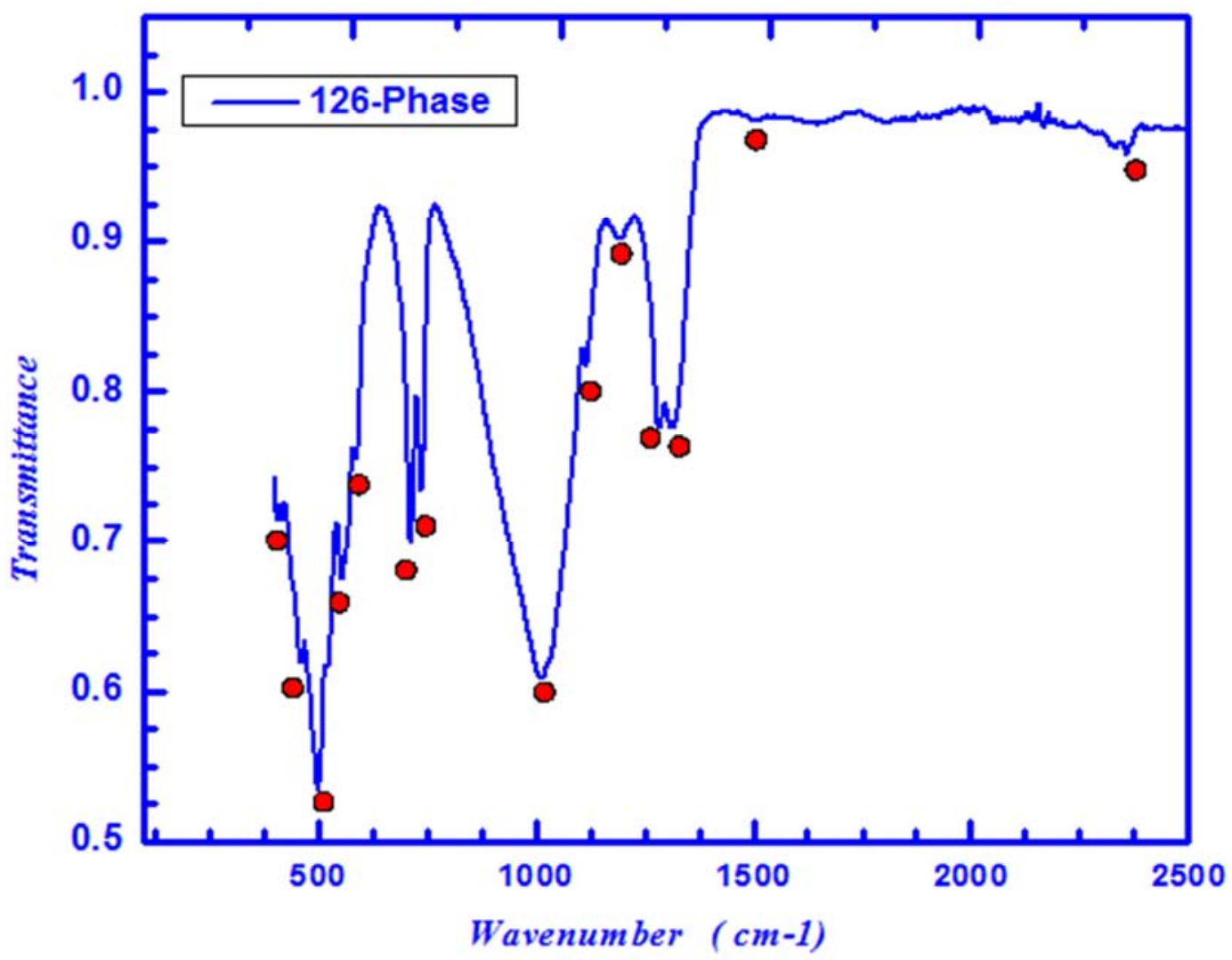

Fig. 2. Infrared spectra recorded for $\mathrm{Co}_{2} \mathrm{P}_{4} \mathrm{O}_{12}$ (126-Phase $=\mathrm{AB}_{2} \mathrm{X}_{6}$ structure type) after firing process and sintering at $1100^{\circ} \mathrm{C}$.

\subsection{Scanning Electron Microscopy (SEM) and EDX- Elemental Analysis (EDX)}

Figure 3a shows scanning electron micrograph recorded for cobalt cyclotetraphosphate synthesized at $1100^{\circ} \mathrm{C}$, it is so difficult to observe inhomogeneitiy within the micrograph due to that the powders used are very fine and the grain size estimated is too small. The average grain size was estimated from SE-micrograph and found to be ranged in between 3.2$3.78 \mu \mathrm{m}$ which is relatively high in contrast with data estimated from XRD through Scherrer's equation $(D=0.98$ $\mu \mathrm{m})$. This indicates that the actual grain size in the material bulk could be smaller than that detected on the surface morphology. Furthermore, in our EDX (energy disperse Xray) analysis as shown in Fig. $3 \mathrm{~b}$ and Table. 1, the molar ratios of cobalt cyclotetraphosphate was detected qualitatively with very good fitting to the actual molar ratio (1:2:6) as shown in Table 1 .

The EDX examinations were performed on random spots within the same sample to confirm accuracy of calculations molar ratios of cobalt cyclotetraphosphateas possible. 


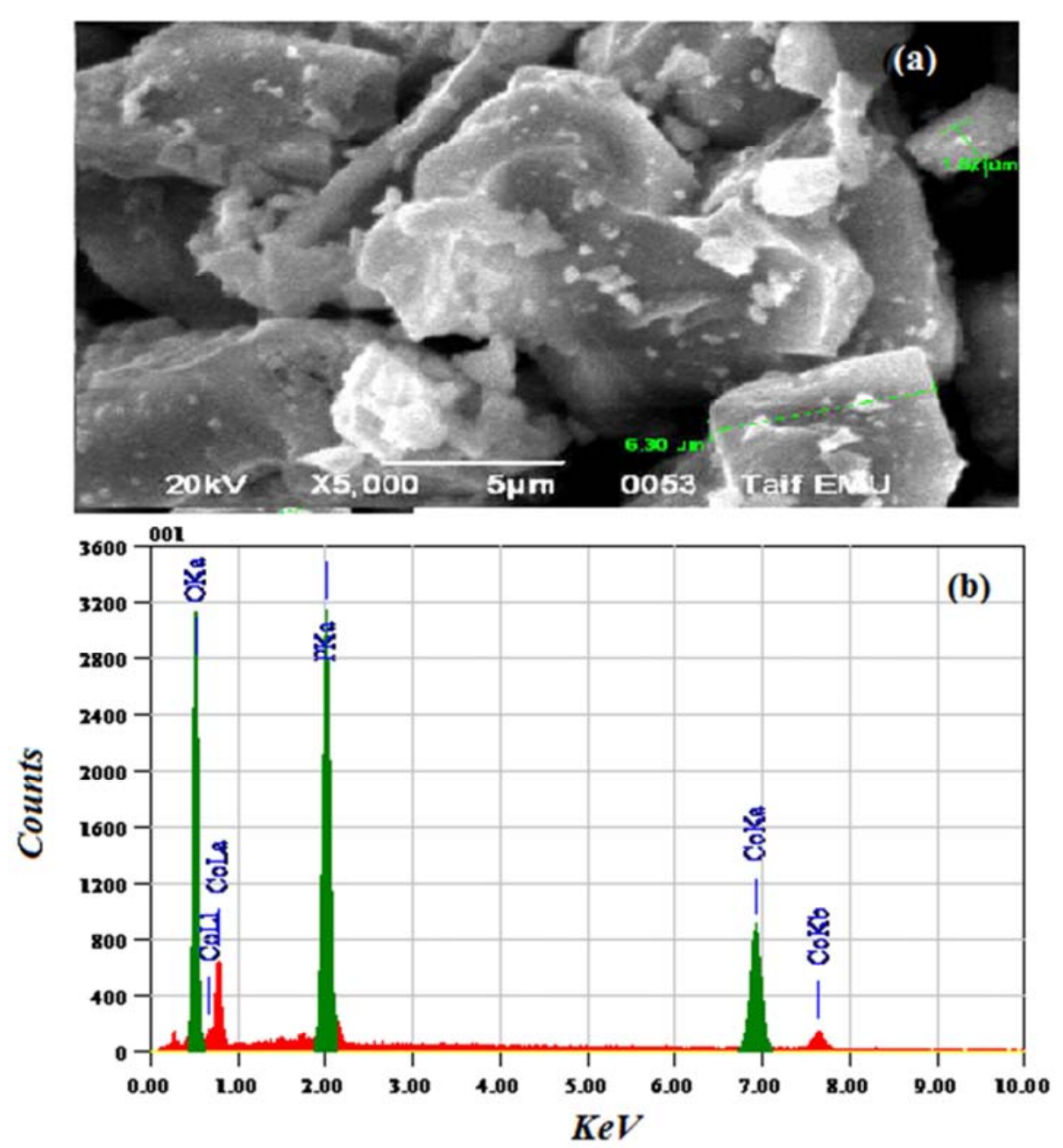

Fig. 3. (a): Scanning electron micrograph recorded for cobalt cyclotetraphosphate synthesized at $1100^{\circ} \mathrm{C}$ with average grain size ranged in between $3.2-3.78$ um. (b): EDX-elemental analysis spectrogram recorded for $\mathrm{Co}_{2} \mathrm{P}_{4} \mathrm{O}_{12}$

Table. 1. EDX elemental analysis ratios for $\mathrm{Co}_{2} \mathrm{P}_{4} \mathrm{O}_{12}$.

\begin{tabular}{llllll}
\hline Element & $\mathbf{( k e V )}$ & Mass\% & Error\% & Atom\% & K \\
O K & 0.525 & 46.24 & 0.15 & 69.47 & 49.4435 \\
P K & 2.013 & 23.36 & 0.12 & 19.13 & 22.6434 \\
Co K & 6.924 & 30.39 & 0.44 & 11.40 & 27.9131 \\
Total & 100.00 & & 100.00 & & \\
\hline
\end{tabular}

\subsection{Atomic Force Investigations (AFM)}

Figure. 4 shows 3D-AFM-micrograph tapping mode image captured for scanned area $0.1 \mu \mathrm{m}^{2}$.

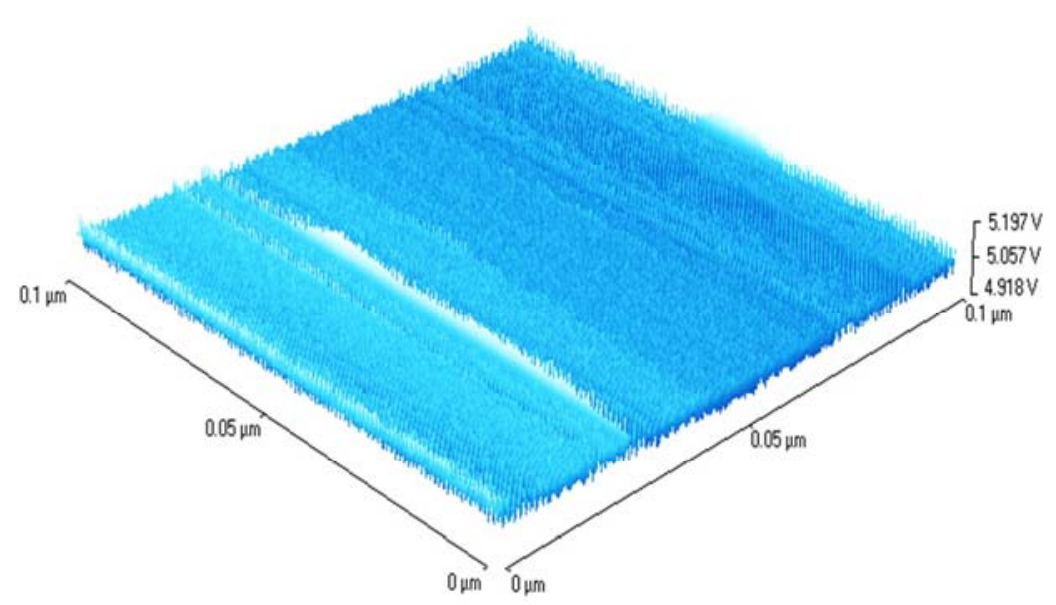

Fig. 4. 3D-AFM-micrograph tapping mode image recorded for scanned area $0.1 \mu m^{2}$ of cobaltcyclotetraphosphate $\left(\mathrm{Co}_{2} \mathrm{P}_{4} \mathrm{O}_{12}\right)$. 
Of cobalt cyclotetraphosphate $\left(\mathrm{Co}_{2} \mathrm{P}_{4} \mathrm{O}_{12}\right)$. The image was constructed by application tapping mode with slow scan rate and high resolution imaging with 1024 line per $0.1 \mathrm{~nm}$. The tapping amplitude current was monitored as a function of line drawing heights. For more accurate surface analysis AFMraw data was forwarded to Origin Lab program version 7 and the data are converted into matrix then $3 \mathrm{D}$-contour surface mapping is constructed as shown in Figure 5a.

Figure 5a displays 3D-visualized-contour plot of AFM- micrograph surface imagingcaptured forscanned area $0.2 \mu \mathrm{m}^{2}$ of cobalt cyclotetraphosphate $\left(\mathrm{Co}_{2} \mathrm{P}_{4} \mathrm{O}_{12}\right)$. To increase the accuracy of analysis of this image the data were forwarded to plot Fig. $5 \mathrm{~b}$ which is $2 \mathrm{D}$-visualized-contour plot of the same image $\mathrm{f}$ cobalt cyclotetraphosphate $\left(\mathrm{Co}_{2} \mathrm{P}_{4} \mathrm{O}_{12}\right)$. The analysis of the surface nature and morphology enhance us to understand application of such these materialsmetal cyclotetraphosphate $\left(\mathrm{M}_{2} \mathrm{P}_{4} \mathrm{O}_{12}\right)$ as colorant materials in coating and ceramic industry.

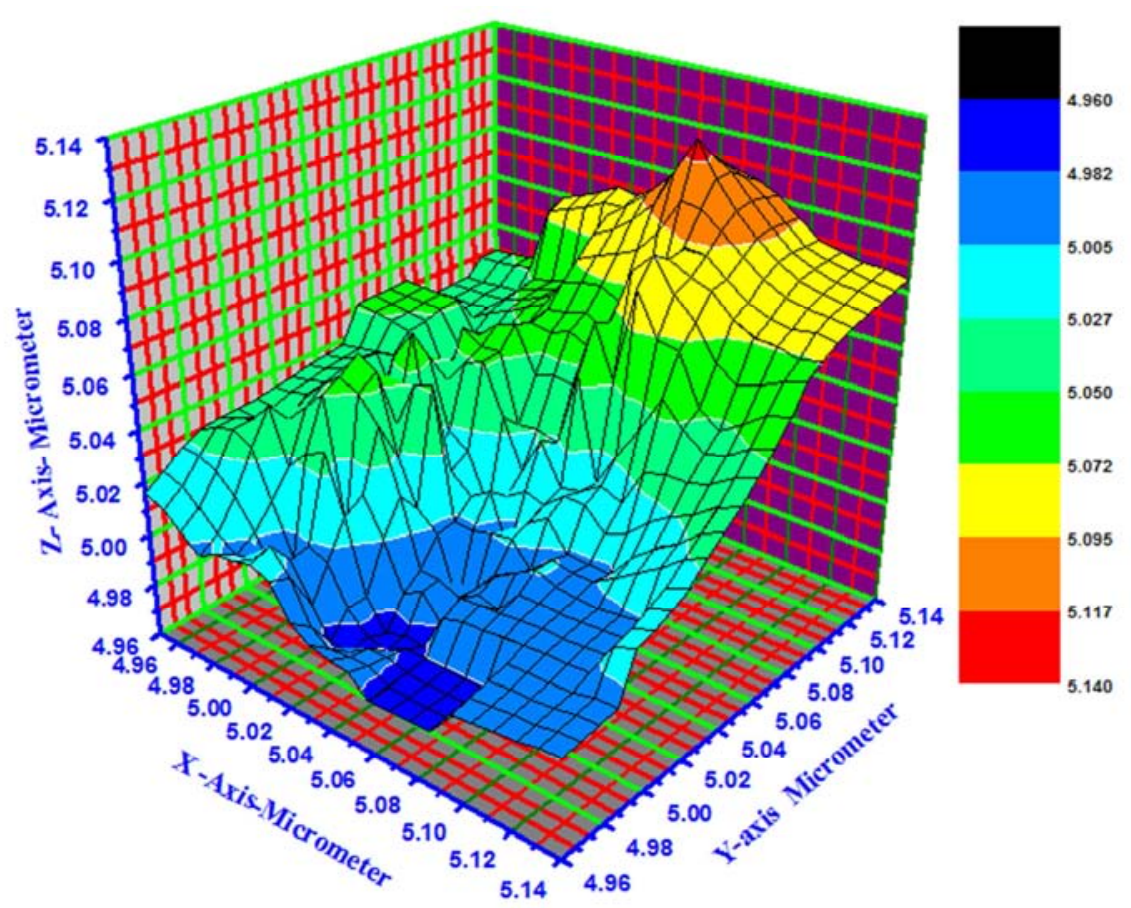

Fig. 5a. 3D-visualized-contour plot of AFM-micrograph surface image recorded for scanned area $0.2 \mu m^{2}$ of cobalt cyclotetraphosphate $\left(\mathrm{Co}_{2} \mathrm{P}_{4} \mathrm{O}_{12}\right)$.

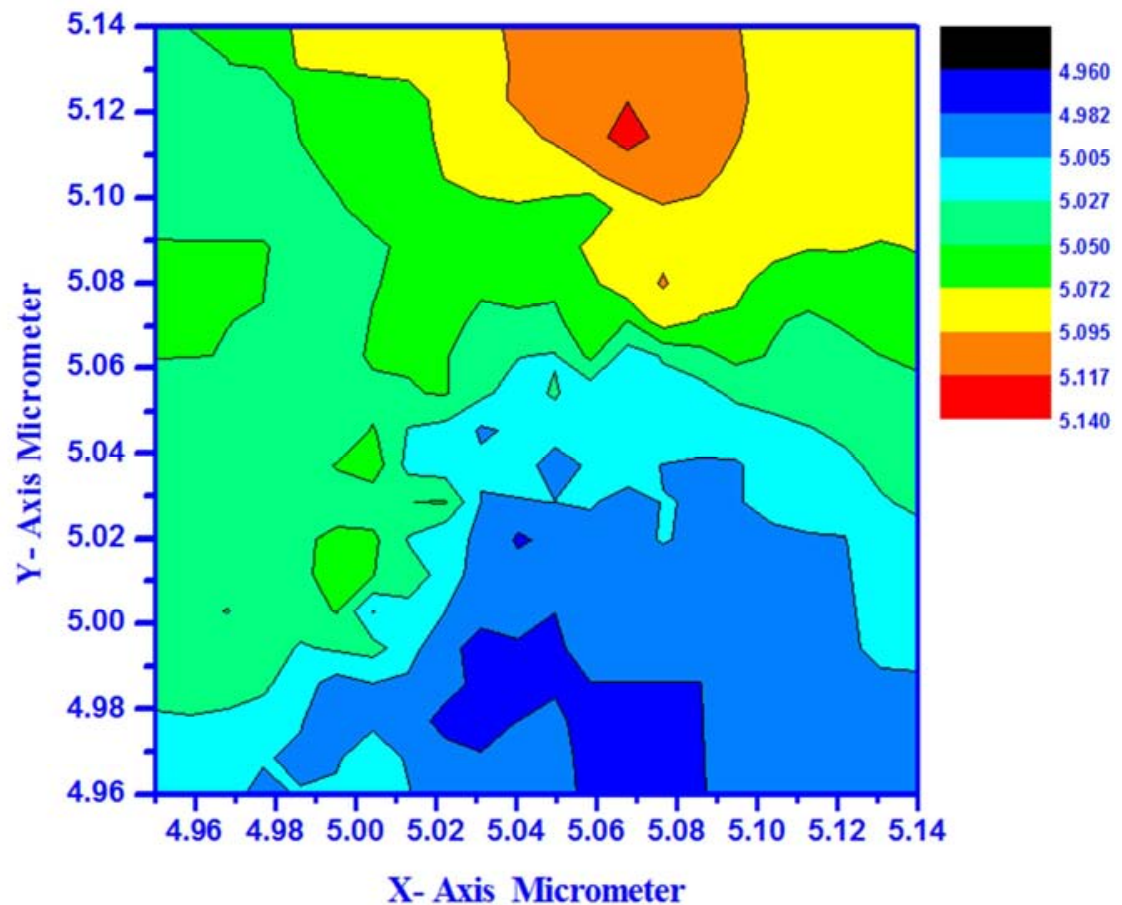

Fig. 5b. 2D-visualized-contour plot of AFM-micrograph tapping mode image recorded for scanned area $0.2 \mu m^{2}$ of cobalt cyclotetraphosphate $\left(\right.$ Co $\left.{ }_{2} P_{4} O_{12}\right)$. 
The AFM-tapping mode captured image can be divided into three zones $1^{\text {st }}$ zone include (yellow, orange and red color) this zone represents $\sim 21 \%$ of the whole scanned area which is equal $\sim 0.042 \mu \mathrm{m}^{2}$, the surface heights in this zone ranged in between $6.072-6.14 \mu \mathrm{m}$ as clear in the key-image. The red zone represents $2 \%=0.004 \mu \mathrm{m}^{2}$ which processes the highest height on the scanned area with height $\max =6.14$ $\mu \mathrm{m}$. The second zone represents $\sim$ [dark green zone $(23 \%)+$ pale green zone $(18 \%)]$ which represents $\sim 41 \%\left(0.082 \mu \mathrm{m}^{2}\right)$ from the whole scanned area with heights gradient ranged in between $6.027-6.06 \mu \mathrm{m}$. The $3^{\text {rd }}$ zone occupies $\sim 38 \%=$ $0.076 \mu \mathrm{m}^{2}$ from the whole scanned area with heights gradient lies in between $4.88-6.06 \mu \mathrm{m}$. The average grain size was estimated from AFM-analysis and found in between 56-80 $\mathrm{nm}$ which is nearly matched with that calculated from XRD through applying Scherrer's formula $\sim(98 \mathrm{~nm})$. The differences in the values of average grain sizes calculated via SEM, AFM and Scherrer's formula are good evidence for existence gradient in the grain sizes in the bulk which are completely different than those on the surface layers.

\subsection{Structural Visualization Studies}

Figure 6 displays the unit cell of cobaltcyclotetraphosphate which built up via DIAMOND IMPACT CRYSTAL PROGRAM version 3.2 depending up on the single crystal data and atomic coordinates locations of pure cobalt cyclotetraphsphate. The unit cell was visualized and built up with minimum 138 atoms $=(\mathrm{Co}=16, \mathrm{P}=38$ and $\mathrm{O}=94$ atoms) and four edges. A visualization study made is concerned by matching and comparison of experimental and theoretical data of atomic positions, bond distances, oxidation states and bond torsion on the crystal structure formed.

Many researchers in the last did their best to understand the crystallographic structure of phosphates (open phosphates or cyclic poly phosphates) [20-28].

The initial analysis of structural parameters inside visualized crystal lattice of cobalt cyclotetraphosphate indicated that there are two different types of cobalt namely (Co1 and Co2), Two types of phosphorous atoms (P1 and P2) and finally six different types of oxygen atoms namely (O1, $\mathrm{O} 2, \mathrm{O} 3, \mathrm{O} 4, \mathrm{O} 5$ and O6).

The comparison between visualized XRD-profile Figure 7 and the experimental XRD-pattern sintered at $1100^{\circ} \mathrm{C}$ Figure
1 indicated that there is type of fitting coupled with high figure of merit between both patterns specially on the point of view positions of most intense reflection peaks on both patterns. The shifts on some intense reflection peak position within limits of two theta values $\sim 2$ degree could due to impurity phases interactions with the main monoclinic structure of cobalt cyclotetraphosphate on the experimental pattern.

Figure 8 displays the regular distribution of $\mathrm{PO}_{3}$-polyhera throughout the unit cell of cobalt

cyclotetraphosphate. The analysis of these polyhedron indicated that the phosphorous atom as central ion was surrounding by oxygen atoms, three oxygen atoms represents the triangle base lie at $\sim$ nearly the same distance from phosphorous (central metal ion) while the forth one at distance longer than the others three oxygen of triangle base.

The accurate analysis of bond lengths, torsion on angles inside the crystal lattice of cobalt cyclotetraphosphate (Tables 2-11) can enhance us understand what is the structural factors responsible for lattice stability.

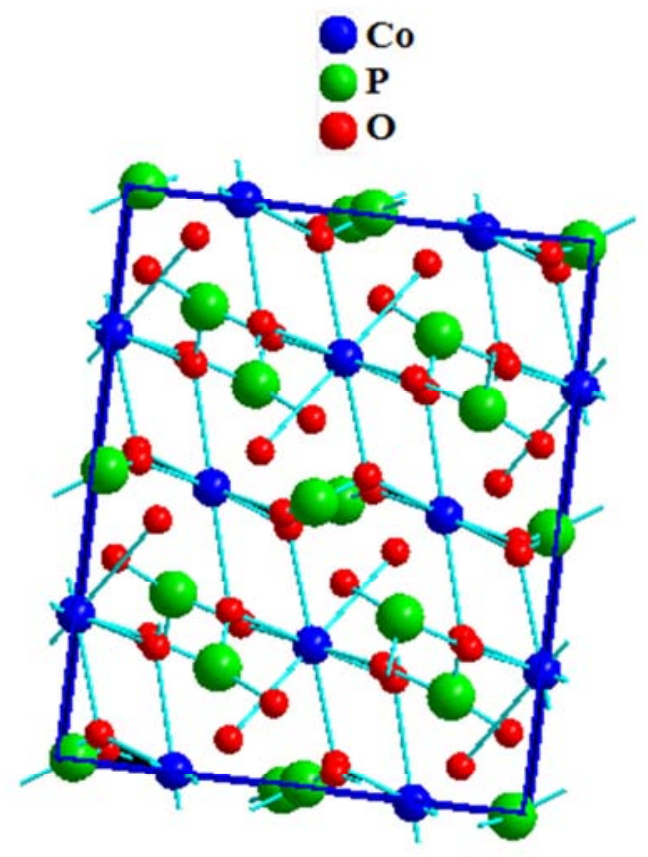

\section{Co2P4O12 Structure with C12/C1 Space Group and Monoclinic AB2X6 Structure Type}

Fig. 6. Unit cell of monoclinic cobalt cyclotetraphosphate.

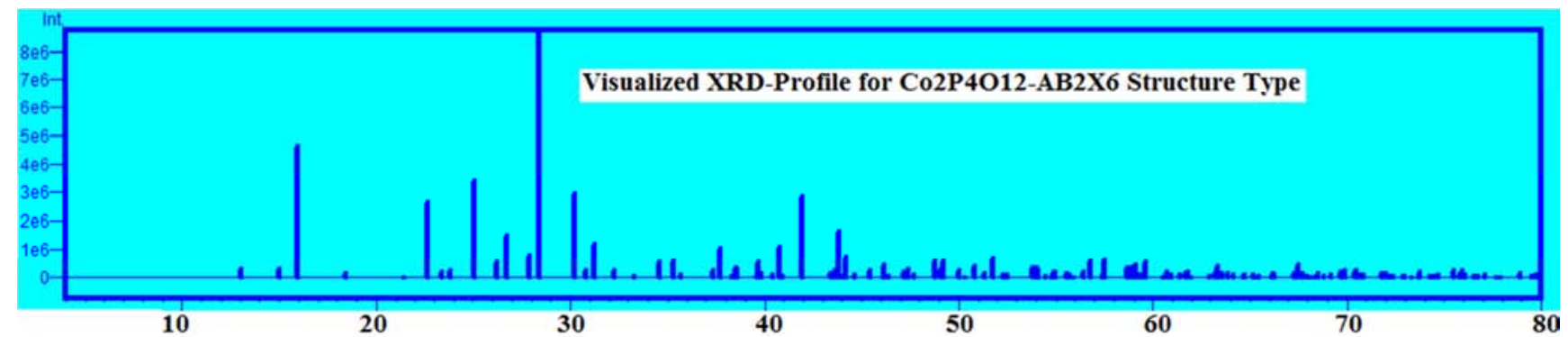

Fig. 7. Visualized XRD-profile constructed for monoclinic $\mathrm{Co}_{2} \mathrm{P}_{4} \mathrm{O}_{12}$ with $\mathrm{C12} / \mathrm{C1}$ space group 


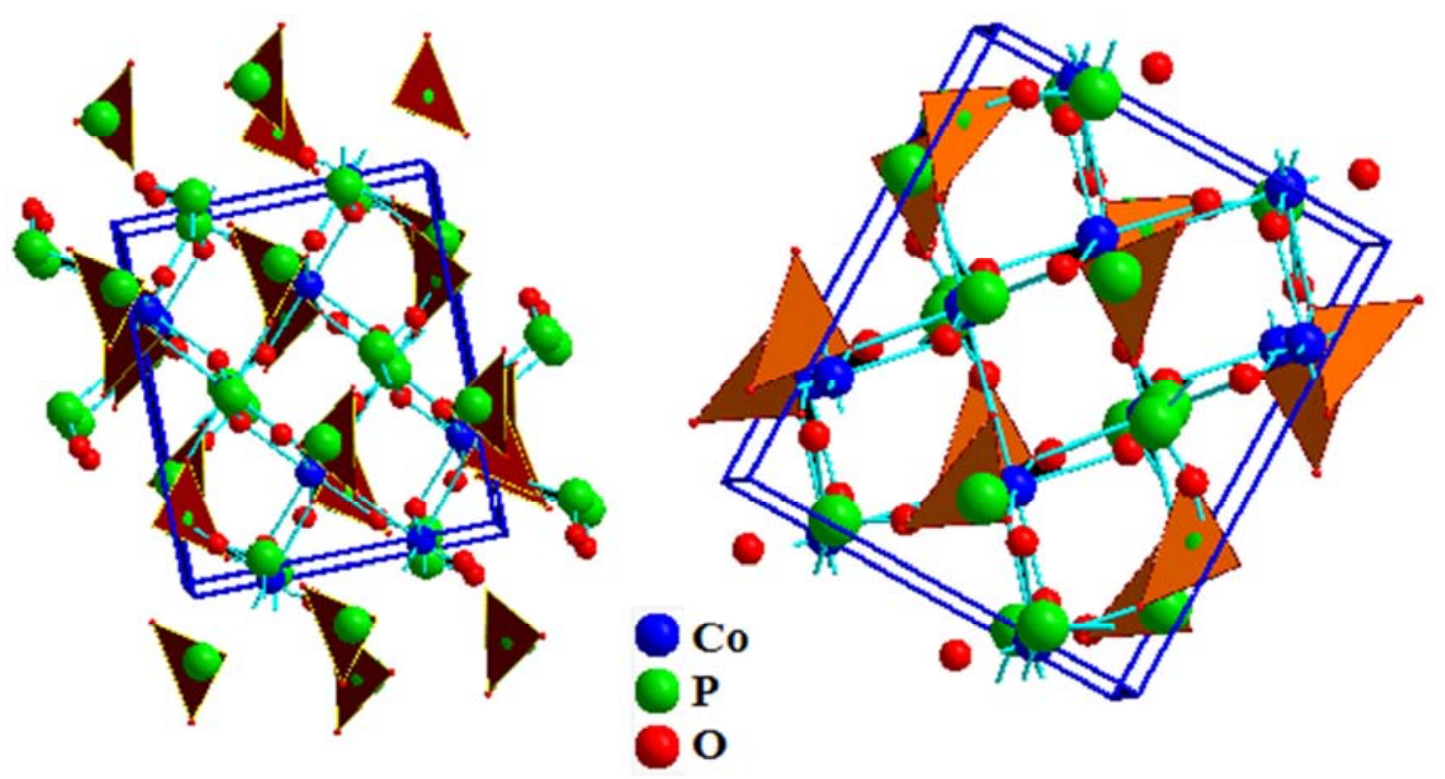

PO3-Polyhedra in M2P4O12

Fig. 8. Distribution of $\mathrm{PO}_{3}$-polyheral in the unit cell of cobalt cyclotetraphosphate.

Table 2. Selected bond lengths and angles inside crystal lattice of $\mathrm{Co}_{2} \mathrm{P}_{4} \mathrm{O}_{12}$.

\begin{tabular}{llllll}
\hline Atom1 & Atom2 & $\mathbf{d 1 - 2} \AA$ & Atom3 & $\mathbf{d 1 - 3} \AA$ & Angle 312 $^{\wedge}$ \\
\hline Co1 & O1 & 2.0927 & O1 & 2.0927 & 180.000 \\
& O1 & 2.0927 & O2 & 2.3366 & 82.238 \\
& O1 & 2.0927 & O2 & 2.3366 & 97.762 \\
& O2 & 2.3366 & O2 & 2.3366 & 180.000 \\
& O2 & 2.3366 & O5 & 2.4865 & 116.323 \\
& O5 & 2.4865 & O3 & 2.8210 & 57.061 \\
& O5 & 2.4865 & P1 & 3.0353 & 157.072 \\
& O3 & 2.8210 & O3 & 2.8210 & 180.000 \\
& O3 & 2.8210 & P2 & 2.9164 & 144.014 \\
& P2 & 2.9164 & P2 & 2.9164 & 180.000 \\
P2 & 2.9164 & P1 & 3.0353 & 71.568 \\
& P2 & 2.9164 & O4 & 3.5270 & 29.627 \\
& P2 & 2.9164 & O6 & 3.5756 & 80.753 \\
& P1 & 3.0353 & P1 & 3.0353 & 180.000 \\
& P1 & 3.0353 & O6 & 3.5756 & 21.363 \\
& O4 & 3.5270 & O6 & 3.5756 & 96.488 \\
& O4 & 3.5270 & O6 & 3.5756 & 83.512 \\
O6 & 3.5756 & O6 & 3.5756 & 180.000 \\
& O6 & 3.5756 & P2 & 3.6583 & 79.758 \\
O6 & 3.5756 & P2 & 3.6583 & 100.242 \\
\hline
\end{tabular}

\begin{tabular}{llllll}
\hline Atom1 & Atom2 & $\mathbf{d 1 - 2} \AA$ & Atom3 & $\mathbf{d 1 - 3} \AA$ & Angle 312 $^{\wedge}$ \\
\hline P1 & 3.1577 & O4 & 3.5398 & 93.099 \\
P1 & 3.1577 & O3 & 3.9043 & 107.617 \\
P1 & 3.1577 & O3 & 3.9043 & 136.556 \\
O6 & 3.3434 & O6 & 3.3434 & 160.281 \\
O6 & 3.3434 & P1 & 3.4087 & 138.822 \\
O6 & 3.3434 & O1 & 3.5271 & 113.415 \\
P1 & 3.4087 & P1 & 3.4087 & 79.006 \\
P1 & 3.4087 & O1 & 3.5271 & 84.012 \\
P1 & 3.4087 & O1 & 3.5271 & 67.309 \\
P1 & 3.4087 & O4 & 3.5398 & 103.558 \\
O1 & 3.5271 & P2 & 3.7464 & 25.747 \\
O1 & 3.5271 & P2 & 3.7464 & 144.026 \\
O1 & 3.5271 & O3 & 3.9043 & 56.224 \\
O1 & 3.5271 & O3 & 3.9043 & 87.439 \\
O4 & 3.5398 & O4 & 3.5398 & 88.346 \\
O4 & 3.5398 & P2 & 3.7464 & 74.116 \\
O4 & 3.5398 & P2 & 3.7464 & 118.697 \\
P2 & 3.7464 & O3 & 3.9043 & 72.236 \\
P2 & 3.7464 & O3 & 3.9043 & 91.882 \\
P2 & 3.7464 & O3 & 3.9043 & 91.882 \\
P2 & 3.7464 & O3 & 3.9043 & 72.236 \\
O3 & 3.9043 & O3 & 3.9043 & 37.949 \\
\hline
\end{tabular}

Table 3. Selected bond lengths and angles inside crystal lattice of $\mathrm{Co}_{2} \mathrm{P}_{4} \mathrm{O}_{12}$.

\begin{tabular}{llllll}
\hline Atom1 & Atom2 & d1-2 $\AA$ & Atom3 & d1-3 $\AA$ & Angle 312^ $^{\wedge}$ \\
\hline Co2 & O6 & 2.1694 & O6 & 2.1694 & 93.593 \\
& O6 & 2.1694 & O5 & 2.3208 & 84.836 \\
& O6 & 2.1694 & O5 & 2.3208 & 174.602 \\
& O6 & 2.1694 & O2 & 2.5737 & 112.127 \\
& O6 & 2.1694 & O2 & 2.5737 & 71.914 \\
& O5 & 2.3208 & O4 & 3.5398 & 76.791 \\
& O5 & 2.3208 & P2 & 3.7464 & 74.787 \\
& O5 & 2.3208 & P2 & 3.7464 & 116.925 \\
& O5 & 2.3208 & O3 & 3.9043 & 138.211 \\
& O5 & 2.3208 & O3 & 3.9043 & 120.351 \\
& O2 & 2.5737 & O2 & 2.5737 & 174.457 \\
& O2 & 2.5737 & P1 & 3.1577 & 77.031 \\
& O2 & 2.5737 & O6 & 3.3434 & 98.404 \\
& O2 & 2.5737 & O6 & 3.3434 & 80.635 \\
\hline
\end{tabular}

Table 4. Selected bond lengths and angles inside crystal lattice of $\mathrm{Co}_{2} \mathrm{P}_{4} \mathrm{O}_{12}$.

\begin{tabular}{llllll}
\hline Atom1 & Atom2 & d1-2 $\AA$ & Atom3 & d1-3 $\AA$ & Angle 312^ $^{\wedge}$ \\
\hline P1 & O5 & 1.2222 & O6 & 1.3354 & 112.012 \\
& O5 & 1.2222 & O3 & 1.8394 & 111.327 \\
& O5 & 1.2222 & O4 & 1.9623 & 98.852 \\
& O5 & 1.2222 & Co1 & 3.0353 & 52.425 \\
& O6 & 1.3354 & O1 & 3.8450 & 71.883 \\
& O6 & 1.3354 & O6 & 3.9043 & 47.653 \\
& O1 & 3.4635 & O1 & 3.9266 & 106.380 \\
& O1 & 3.4635 & O2 & 3.9527 & 25.309 \\
& O1 & 3.4635 & P1 & 3.9812 & 156.181 \\
& O3 & 1.8394 & Co1 & 3.0353 & 65.455 \\
& O3 & 1.8394 & Co2 & 3.1577 & 148.445 \\
& O4 & 1.9623 & O1 & 3.9266 & 47.041 \\
& O4 & 1.9623 & O2 & 3.9527 & 87.564 \\
& O4 & 1.9623 & P1 & 3.9812 & 64.088 \\
\hline
\end{tabular}




\begin{tabular}{llllll}
\hline Atom1 & Atom2 & $\mathbf{d 1 - 2} \boldsymbol{\AA}$ & Atom3 & $\mathbf{d 1 - 3} \AA$ & Angle 312 $^{\wedge}$ \\
\hline & Co1 & 3.0353 & Co2 & 3.1577 & 83.872 \\
Co1 & 3.0353 & O3 & 3.3910 & 107.797 \\
Co1 & 3.0353 & Co2 & 3.4087 & 90.253 \\
Co2 & 3.1577 & P2 & 3.4815 & 133.588 \\
Co2 & 3.1577 & O1 & 3.5216 & 76.412 \\
O3 & 3.3910 & O1 & 3.8450 & 90.375 \\
Co2 & 3.4087 & O1 & 3.9266 & 108.957 \\
Co2 & 3.4087 & O2 & 3.9527 & 40.078 \\
O2 & 3.5532 & O2 & 3.9527 & 62.931 \\
O2 & 3.5532 & P1 & 3.9812 & 152.445 \\
O3 & 3.4278 & P2 & 3.4815 & 82.722 \\
P2 & 3.4815 & O1 & 3.5216 & 59.248 \\
P2 & 3.5485 & O2 & 3.5982 & 110.496 \\
O4 & 3.5878 & O2 & 3.5982 & 95.547 \\
O4 & 3.5878 & O1 & 3.8450 & 84.205 \\
O4 & 3.5878 & O6 & 3.9043 & 96.550 \\
\hline
\end{tabular}

\begin{tabular}{llllll}
\hline Atom1 & Atom2 & $\mathbf{d 1 - 2} \AA$ & Atom3 & $\mathbf{d 1 - 3} \AA$ & Angle 312 $^{\wedge}$ \\
\hline & O3 & 3.5174 & O3 & 3.8471 & 157.065 \\
& O3 & 3.5174 & P1 & 3.9266 & 159.635 \\
& P1 & 3.5216 & Co2 & 3.5271 & 163.460 \\
P1 & 3.5216 & O6 & 3.6570 & 129.656 \\
& Co2 & 3.5271 & P1 & 3.9266 & 118.457 \\
& O6 & 3.6570 & P2 & 3.7128 & 70.152 \\
P2 & 3.7128 & P1 & 3.9266 & 148.032 \\
O5 & 3.7359 & O6 & 3.7769 & 79.868 \\
O5 & 3.7359 & P1 & 3.8450 & 18.483 \\
O5 & 3.7359 & O3 & 3.8471 & 140.930 \\
O5 & 3.7359 & P1 & 3.9266 & 120.490 \\
O6 & 3.7769 & O3 & 3.8471 & 138.211 \\
O6 & 3.7769 & P1 & 3.9266 & 141.255 \\
P1 & 3.8450 & O3 & 3.8471 & 159.386 \\
O3 & 3.8471 & P1 & 3.9266 & 27.350 \\
\hline
\end{tabular}

Table 5. Selected bond lengths and angles inside crystal lattice of $\mathrm{Co}_{2} \mathrm{P}_{4} \mathrm{O}_{12}$.

\begin{tabular}{llllll}
\hline Atom1 & Atom2 & $\mathbf{d 1 - 2} \AA$ & Atom3 & $\mathbf{d 1 - 3} \AA$ & Angle 312^ $^{\wedge}$ \\
\hline P2 & O2 & 1.3584 & O1 & 1.6346 & 90.263 \\
& O2 & 1.3584 & O4 & 1.7500 & 122.795 \\
& O1 & 1.6346 & O5 & 3.8101 & 159.446 \\
& O1 & 1.6346 & O4 & 3.8181 & 47.186 \\
& O1 & 1.6346 & O5 & 3.8547 & 102.964 \\
& O4 & 1.7500 & O3 & 1.7746 & 85.307 \\
& O4 & 1.7500 & Co1 & 2.9164 & 94.901 \\
O3 & 1.7746 & O5 & 3.8101 & 34.432 \\
& O3 & 1.7746 & O5 & 3.8547 & 105.956 \\
Co1 & 2.9164 & O5 & 3.4562 & 164.249 \\
Co1 & 2.9164 & O1 & 3.4618 & 37.075 \\
& O5 & 3.4562 & O4 & 3.8181 & 61.446 \\
O5 & 3.4562 & O5 & 3.8547 & 151.691 \\
O1 & 3.4618 & P1 & 3.4815 & 60.953 \\
O1 & 3.4618 & P1 & 3.5485 & 68.115 \\
P1 & 3.5485 & O5 & 3.8101 & 69.465 \\
P1 & 3.5485 & O4 & 3.8181 & 128.505 \\
P1 & 3.5485 & O5 & 3.8547 & 127.918 \\
O6 & 3.5725 & O3 & 3.5777 & 169.950 \\
O6 & 3.5725 & Co1 & 3.6583 & 84.063 \\
O3 & 3.5777 & O4 & 3.8181 & 51.319 \\
O3 & 3.5777 & O5 & 3.8547 & 130.744 \\
Co1 & 3.6583 & O2 & 3.7104 & 36.966 \\
Co1 & 3.6583 & O1 & 3.7128 & 122.659 \\
O5 & 3.6692 & O5 & 3.8547 & 147.193 \\
O2 & 3.7104 & O1 & 3.7128 & 156.019 \\
Co2 & 3.7464 & O5 & 3.8547 & 35.519 \\
O5 & 3.8101 & O4 & 3.8181 & 112.308 \\
\hline
\end{tabular}

Table 7. Selected bond lengths and angles inside crystal lattice of $\mathrm{Co}_{2} \mathrm{P}_{4} \mathrm{O}_{12}$.

\begin{tabular}{llllll}
\hline Atom1 & Atom2 & $\mathbf{d 1 - 2} \AA$ & Atom3 & $\mathbf{d 1 - 3} \AA$ & Angle 312$^{\wedge}$ \\
\hline O2 & P2 & 1.3584 & O1 & 2.1302 & 50.116 \\
& P2 & 1.3584 & Co1 & 2.3366 & 100.899 \\
& O1 & 2.1302 & O6 & 3.8732 & 144.603 \\
& O1 & 2.1302 & O6 & 3.9416 & 66.484 \\
& O1 & 2.1302 & P1 & 3.9527 & 94.733 \\
Co1 & 2.3366 & O5 & 2.5475 & 61.027 \\
O5 & 2.5475 & O6 & 3.8732 & 30.571 \\
O5 & 2.5475 & O6 & 3.9416 & 84.546 \\
Co2 & 2.5737 & O6 & 3.9416 & 30.654 \\
Co2 & 2.5737 & P1 & 3.9527 & 58.507 \\
O3 & 2.6359 & O4 & 2.7355 & 52.758 \\
O3 & 2.6359 & O6 & 2.8042 & 141.814 \\
O4 & 2.7355 & O6 & 3.9416 & 116.394 \\
O4 & 2.7355 & P1 & 3.9527 & 78.086 \\
O6 & 2.8042 & O1 & 2.9186 & 126.931 \\
O6 & 2.8042 & O1 & 3.3406 & 83.218 \\
O6 & 2.8042 & O4 & 3.5756 & 115.388 \\
O6 & 2.8042 & P1 & 3.5982 & 63.049 \\
O6 & 2.8042 & P2 & 3.7104 & 126.522 \\
O6 & 2.8042 & O6 & 3.9416 & 52.695 \\
O6 & 2.8042 & P1 & 3.9527 & 11.746 \\
O1 & 2.9186 & O1 & 3.3406 & 83.639 \\
O1 & 2.9186 & O4 & 3.5756 & 52.764 \\
O1 & 2.9186 & P1 & 3.5982 & 64.434 \\
O4 & 3.5756 & O6 & 3.9416 & 73.486 \\
P1 & 3.5982 & P2 & 3.7104 & 73.993 \\
P1 & 3.5982 & O6 & 3.8732 & 20.160 \\
\hline
\end{tabular}

Table 8. Selected bond lengths and angles inside crystal lattice of $\mathrm{Co}_{2} \mathrm{P}_{4} \mathrm{O}_{12}$.

Table 6. Selected bond lengths and angles inside crystal lattice of $\mathrm{Co}_{2} \mathrm{P}_{4} \mathrm{O}_{12}$.

\begin{tabular}{|lllll|l}
\hline Atom1 & Atom2 & d1-2 $\AA$ & Atom3 & d1-3 $\AA$ & Angle 312 $^{\wedge}$ \\
\hline O1 & P2 & 1.6346 & Co1 & 2.0927 & 157.754 \\
& P2 & 1.6346 & O2 & 2.1302 & 39.621 \\
& P2 & 1.6346 & P1 & 3.9266 & 82.859 \\
& Co1 & 2.0927 & O2 & 2.1302 & 151.780 \\
& Co1 & 2.0927 & O5 & 2.6771 & 61.400 \\
& O2 & 2.1302 & O6 & 3.6570 & 81.232 \\
& O2 & 2.1302 & P2 & 3.7128 & 114.101 \\
& O2 & 2.9186 & O4 & 2.9451 & 75.146 \\
& O2 & 2.9186 & O4 & 2.9609 & 129.658 \\
& O4 & 2.9451 & O5 & 3.7359 & 138.844 \\
& O4 & 2.9451 & O6 & 3.7769 & 69.906 \\
& O3 & 3.0569 & O2 & 3.3406 & 135.391 \\
& O3 & 3.0569 & P2 & 3.4618 & 113.44 \\
& O2 & 3.3406 & P1 & 3.9266 & 79.250 \\
& P2 & 3.4618 & O3 & 3.5075 & 29.494 \\
\hline
\end{tabular}

\begin{tabular}{llllll}
\hline Atom1 & Atom2 & $\mathbf{d 1 - 2} \AA$ & Atom3 & $\mathbf{d 1 - 3 ~ \AA}$ & Angle 312 $^{\wedge}$ \\
\hline O3 & P2 & 1.7746 & P1 & 1.8394 & 148.861 \\
& P2 & 1.7746 & O4 & 2.3882 & 46.911 \\
& P1 & 1.8394 & O4 & 3.2099 & 33.597 \\
& P1 & 1.8394 & O6 & 3.3713 & 92.284 \\
P1 & 1.8394 & P1 & 3.3910 & 108.337 \\
& O4 & 2.3882 & P2 & 3.5777 & 102.290 \\
& O4 & 2.3882 & O3 & 3.7969 & 57.227 \\
& O4 & 2.3882 & O1 & 3.8471 & 88.198 \\
& O3 & 2.5389 & O5 & 2.5520 & 126.753 \\
& O3 & 2.5389 & O6 & 2.5691 & 82.598 \\
& O3 & 2.5389 & O2 & 2.6359 & 123.991 \\
& O5 & 2.5520 & Co1 & 2.8210 & 54.856 \\
& O5 & 2.5520 & O1 & 3.0569 & 146.390 \\
& O6 & 2.5691 & O4 & 3.2099 & 55.840 \\
& O2 & 2.6359 & O6 & 3.3713 & 98.001 \\
& O2 & 2.6359 & P1 & 3.3910 & 99.094 \\
& O2 & 2.6359 & P1 & 3.4278 & 99.516 \\
\hline
\end{tabular}




\begin{tabular}{llllll}
\hline Atom1 & Atom2 & $\mathbf{d 1 - 2} \AA$ & Atom3 & $\mathbf{d 1 - 3} \AA$ & Angle 312 $^{\wedge}$ \\
\hline O2 & 2.6359 & O5 & 3.4479 & 108.342 \\
Co1 & 2.8210 & O4 & 3.2099 & 103.234 \\
Co1 & 2.8210 & O6 & 3.3713 & 102.506 \\
O1 & 3.0569 & P1 & 3.4278 & 89.823 \\
O4 & 3.2099 & P1 & 3.3910 & 112.702 \\
O4 & 3.2099 & P1 & 3.4278 & 65.342 \\
O4 & 3.2099 & O5 & 3.4479 & 68.024 \\
O4 & 3.2099 & O1 & 3.5075 & 83.165 \\
O4 & 3.2099 & O1 & 3.5174 & 119.071 \\
O6 & 3.3713 & O1 & 3.8471 & 97.213 \\
P1 & 3.3910 & P1 & 3.4278 & 131.958 \\
P1 & 3.3910 & O5 & 3.4479 & 111.574 \\
O5 & 3.4479 & O1 & 3.8471 & 42.620 \\
O5 & 3.4479 & Co2 & 3.9043 & 143.431 \\
O1 & 3.5075 & O1 & 3.5174 & 73.138 \\
O1 & 3.5075 & P2 & 3.5777 & 142.989 \\
O3 & 3.7969 & O1 & 3.8471 & 54.622 \\
O3 & 3.7969 & Co2 & 3.9043 & 123.375 \\
O1 & 3.8471 & Co2 & 3.9043 & 100.918 \\
\hline
\end{tabular}

Table 9. Selected bond lengths and angles inside crystal lattice of $\mathrm{Co}_{2} \mathrm{P}_{4} \mathrm{O}_{12}$.

\begin{tabular}{llllll}
\hline Atom1 & Atom2 & $\mathbf{d 1 - 2} \AA$ & Atom3 & $\mathbf{d 1 - 3} \AA$ & Angle 312 $^{\wedge}$ \\
\hline O4 & P2 & 1.7500 & P1 & 1.9623 & 145.774 \\
& P2 & 1.7500 & O3 & 2.3882 & 47.781 \\
& P1 & 1.9623 & O5 & 3.7632 & 92.572 \\
& P1 & 1.9623 & P2 & 3.8181 & 82.582 \\
& P1 & 1.9623 & O6 & 3.9110 & 148.016 \\
O3 & 2.3882 & O5 & 2.4663 & 90.497 \\
O3 & 2.3882 & O2 & 2.7355 & 61.479 \\
& O3 & 2.3882 & O6 & 3.9110 & 106.905 \\
O5 & 2.4663 & O6 & 2.7645 & 47.431 \\
& O5 & 2.4663 & O6 & 3.9110 & 156.105 \\
O2 & 2.7355 & O6 & 2.7645 & 167.476 \\
O2 & 2.7355 & O1 & 2.9451 & 43.854 \\
& O2 & 2.7355 & O6 & 3.9110 & 45.808 \\
O6 & 2.7645 & O1 & 2.9451 & 139.841 \\
O6 & 2.7645 & O1 & 2.9609 & 103.240 \\
O1 & 2.9451 & O1 & 2.9609 & 115.526 \\
O1 & 2.9451 & O3 & 3.2099 & 146.973 \\
O1 & 2.9609 & O5 & 3.7294 & 45.394 \\
O3 & 3.2099 & O5 & 3.7632 & 112.476 \\
O3 & 3.2099 & P2 & 3.8181 & 60.469 \\
O3 & 3.2099 & O6 & 3.9110 & 144.539 \\
O4 & 3.3886 & Co1 & 3.5270 & 99.147 \\
O4 & 3.3886 & O2 & 3.5756 & 72.211 \\
Co1 & 3.5270 & P2 & 3.8181 & 59.587 \\
Co1 & 3.5270 & O6 & 3.9110 & 67.403 \\
Co2 & 3.5398 & O2 & 3.5756 & 42.407 \\
Co2 & 3.5398 & P1 & 3.5878 & 116.699 \\
Co2 & 3.5398 & O5 & 3.7294 & 133.664 \\
O2 & 3.5756 & P2 & 3.8181 & 146.783 \\
P1 & 3.5878 & O5 & 3.7294 & 19.104 \\
O5 & 3.7632 & P2 & 3.8181 & 171.945 \\
\hline
\end{tabular}

Table 10. Selected bond lengths and angles inside crystal lattice of $\mathrm{CO}_{2} \mathrm{P}_{4} \mathrm{O}_{12}$.

\begin{tabular}{llllll}
\hline Atom1 & Atom2 & d1-2 $\AA$ & Atom3 & d1-3 $\AA$ & $\begin{array}{l}\text { Angle } \\
\mathbf{3 1 2}^{\wedge}\end{array}$ \\
\hline O5 & P1 & 1.2222 & O6 & 2.1215 & 35.704 \\
& P1 & 1.2222 & Co2 & 2.3208 & 123.015 \\
& O6 & 2.1215 & O4 & 3.7632 & 163.350 \\
& O6 & 2.1215 & P2 & 3.8101 & 86.174 \\
& O6 & 2.1215 & P2 & 3.8547 & 108.843 \\
& Co2 & 2.3208 & O4 & 2.4663 & 95.320 \\
& Co2 & 2.3208 & Co1 & 2.4865 & 118.852 \\
\hline
\end{tabular}

\begin{tabular}{lllll}
\hline O4 & 2.4663 & O4 & 3.7632 & 102.737 \\
O4 & 2.4663 & P2 & 3.8101 & 95.876 \\
Co1 & 2.4865 & P2 & 3.8101 & 49.940 \\
Co1 & 2.4865 & P2 & 3.8547 & 49.159 \\
O2 & 2.5475 & O3 & 2.5520 & 121.976 \\
O2 & 2.5475 & O1 & 2.6771 & 67.870 \\
O3 & 2.5520 & O1 & 3.7359 & 64.870 \\
O3 & 2.5520 & O4 & 3.7632 & 130.063 \\
O3 & 2.5520 & P2 & 3.8101 & 23.154 \\
O1 & 2.6771 & P2 & 3.8101 & 61.610 \\
O1 & 2.6771 & P2 & 3.8547 & 66.467 \\
O6 & 3.0309 & O3 & 3.4479 & 148.096 \\
O6 & 3.0309 & P2 & 3.4562 & 127.948 \\
O3 & 3.4479 & O4 & 3.7632 & 72.449 \\
O3 & 3.4479 & P2 & 3.8101 & 77.786 \\
O3 & 3.4479 & P2 & 3.8547 & 138.847 \\
P2 & 3.4562 & O5 & 3.4814 & 63.859 \\
P2 & 3.4562 & O4 & 3.7294 & 64.063 \\
O5 & 3.4814 & P2 & 3.8101 & 142.125 \\
O5 & 3.4814 & P2 & 3.8547 & 90.676 \\
P2 & 3.6692 & O4 & 3.7294 & 79.797 \\
P2 & 3.6692 & O1 & 3.7359 & 157.355 \\
P2 & 3.6692 & O4 & 3.7632 & 78.546 \\
P2 & 3.6692 & P2 & 3.8101 & 101.543 \\
O4 & 3.7294 & O1 & 3.7359 & 83.831 \\
O4 & 3.7294 & O4 & 3.7632 & 90.906 \\
O4 & 3.7294 & P2 & 3.8101 & 26.815 \\
O1 & 3.7359 & P2 & 3.8547 & 54.240 \\
O4 & 3.7632 & P2 & 3.8101 & 110.453 \\
O4 & 3.7632 & P2 & 3.8547 & 70.438 \\
P2 & 3.8101 & P2 & 3.8547 & 99.099 \\
\hline & & & & \\
\hline
\end{tabular}

Table 11. Selected bond lengths and angles inside crystal lattice of $\mathrm{Co}_{2} \mathrm{P}_{4} \mathrm{O}_{12}$.

\begin{tabular}{|c|c|c|c|c|c|}
\hline Atom1 & Atom2 & d1-2 $\AA$ & Atom3 & d1-3 Å & Angle $312^{\wedge}$ \\
\hline \multirow[t]{29}{*}{ O6 } & P1 & 1.3354 & O5 & 2.1215 & 32.284 \\
\hline & P1 & 1.3354 & $\mathrm{Co} 2$ & 2.1694 & 152.293 \\
\hline & $\mathrm{O} 5$ & 2.1215 & $\mathrm{O} 4$ & 3.9110 & 111.873 \\
\hline & $\mathrm{O} 5$ & 2.1215 & $\mathrm{O} 2$ & 3.9416 & 107.377 \\
\hline & $\mathrm{Co} 2$ & 2.1694 & $\mathrm{O} 3$ & 2.5691 & 110.682 \\
\hline & $\mathrm{Co} 2$ & 2.1694 & $\mathrm{O} 4$ & 2.7645 & 159.226 \\
\hline & $\mathrm{O} 3$ & 2.5691 & P1 & 3.9043 & 58.958 \\
\hline & $\mathrm{O} 3$ & 2.5691 & $\mathrm{O} 4$ & 3.9110 & 116.590 \\
\hline & $\mathrm{O} 3$ & 2.5691 & $\mathrm{O} 2$ & 3.9416 & 83.895 \\
\hline & $\mathrm{O} 4$ & 2.7645 & $\mathrm{O} 2$ & 2.8042 & 102.323 \\
\hline & O6 & 2.7825 & P1 & 3.9043 & 141.347 \\
\hline & $\mathrm{O} 6$ & 2.7825 & $\mathrm{O} 4$ & 3.9110 & 103.379 \\
\hline & O6 & 2.7825 & $\mathrm{O} 2$ & 3.9416 & 82.241 \\
\hline & $\mathrm{O} 2$ & 2.8042 & $\mathrm{O} 5$ & 3.0309 & 51.593 \\
\hline & $\mathrm{O} 2$ & 2.8042 & $\mathrm{O} 6$ & 3.1627 & 82.453 \\
\hline & O5 & 3.0309 & $\mathrm{O} 4$ & 3.9110 & 87.229 \\
\hline & O6 & 3.1627 & $\mathrm{Co} 2$ & 3.3434 & 158.567 \\
\hline & O6 & 3.1627 & $\mathrm{O} 3$ & 3.3713 & 46.169 \\
\hline & $\mathrm{Co} 2$ & 3.3434 & $\mathrm{O} 4$ & 3.9110 & 92.220 \\
\hline & Co2 & 3.3434 & $\mathrm{O} 2$ & 3.9416 & 113.851 \\
\hline & $\mathrm{O} 3$ & 3.3713 & P1 & 3.4154 & 150.720 \\
\hline & $\mathrm{O} 3$ & 3.3713 & P2 & 3.5725 & 80.983 \\
\hline & P1 & 3.4154 & $\mathrm{O} 2$ & 3.9416 & 73.130 \\
\hline & $\mathrm{O} 1$ & 3.7769 & $\mathrm{O} 2$ & 3.9416 & 98.395 \\
\hline & $\mathrm{O} 2$ & 3.8732 & P1 & 3.9043 & 126.294 \\
\hline & $\mathrm{O} 2$ & 3.8732 & $\mathrm{O} 2$ & 3.9416 & 78.676 \\
\hline & P1 & 3.9043 & $\mathrm{O} 4$ & 3.9110 & 99.754 \\
\hline & P1 & 3.9043 & $\mathrm{O} 2$ & 3.9416 & 60.500 \\
\hline & $\mathrm{O} 4$ & 3.9110 & $\mathrm{O} 2$ & 3.9416 & 140.485 \\
\hline
\end{tabular}

The analysis of data in Tables 2, 3, 4 one can conclude the following observations;

Cobalt type one symbolized as (Co1) was linked with all 
types of oxygen atoms recording the following bond lengths $(2.0927,2.3366,2.8210,3.5270,2.4865$ and $3.5756 \mathrm{~A})$ corresponding to Co1-O1, Co1-O2, Co1-O3, Co1-O4, Co1O5 andCo1-O6 bond lengths respectively. From these notifications one can conclude that $\mathrm{O} 1, \mathrm{O} 2$ and $\mathrm{O} 3$ could be located as triangle base of $\mathrm{PO}_{3}$ - while $\mathrm{O} 4, \mathrm{O} 5$ and $\mathrm{O} 6$ can be oriented as axial oxygen to complete the vacant site of tetrahedron forming $\mathrm{PO}^{4-}$ anion.

The cobalt type one (Co1) also is linked with two different types of phosphorous namely (P1 and P2) with bond distances 3.0353 and 2.9164 A respectively which confirm that cobalt has more than one oxidation state over the original common oxidation (CoII and CoIII) inside crystal lattice of cobalt cyclotetraphosphates. Thus could lead to informative scientific knowledge that oxidation state of cobalt takes values between $\mathrm{Co}^{2+}, \mathrm{Co}^{\mathrm{m}+}, \mathrm{Co}^{3+}$ (where $\mathrm{m}$ fractions between 2,3 and $2 \leq \mathrm{m} \leq 3$ ). This result can interpret why the bond lengths of cobalt with six oxygen atoms are different. Plus effect of coupling of charges due to environmental neighboring groups.

Cobalt type two ( $\mathrm{Co} 2)$ has similar behavior to cobalt type one but the oxygen atoms that represent triangle base are recommended to be $\mathrm{O} 2, \mathrm{O} 5$ and $\mathrm{O} 6$ with bond lengths 2.5737,2.3208 and 2.1694A respectively while axial oxygen atoms could be occupied by $\mathrm{O} 1, \mathrm{O} 3$ and $\mathrm{O} 4$ with bond distances 3.5271,3.9043 and 3.5398 A respectively.

The cobalt type two $(\mathrm{Co} 2)$ is also linked with the two different types of phosphorous atoms namely (P1 and P2) with bond distances 3.1577 and $3.7464 \mathrm{~A}$ which confirm that cobalt has more than one oxidation state within the crystal lattice. Similar behavior of existence multi oxidation states was reported in references $[20,21]$ in which the conditions of synthesis at elevated temperatures in air or oxygen were responsible.

With respect to phosphorous atoms (P1 and $\mathrm{P} 2)$ it were observed that phosphorous type one (P1) was linked inside crystal lattice with all oxygen atoms recording bond lengths 1.2222, 1.3334 and 1.9623 A correspond to P1-O5, P1-O6 and $\mathrm{P} 1-\mathrm{O} 4$ respectively these bond distances are suitable to be base triangle of $\mathrm{PO}_{3}$ - while the rest three oxygen atoms $\mathrm{O} 1, \mathrm{O} 2$ and $\mathrm{O} 3$ recorded bond distances $3.4635,3.5532$ and 3.3910 which are suited to be axial atoms.

In conclusion, one can conclude that variations of bond distances between Co1, Co2, P1 and P2 and different six oxygen atoms $(\mathrm{O} 1, \mathrm{O} 2, \mathrm{O} 3, \mathrm{O} 4, \mathrm{O} 5$ and $\mathrm{O} 6)$ inside crystal lattice are responsible for increasing lattice flexibility factor (by controlling in shrinkage and expansion coefficient) and consequently increase itsbonds stability to break. These facts can be attributed to three main factors inside lattice $1^{\text {st }}$ oxidation state of cobalt takes values between $\mathrm{Co}^{2+}, \mathrm{Co}^{\mathrm{m}+}$, $\mathrm{Co}^{3+}$ (where $\mathrm{m}$ fractions between 2,3 and $2 \leq \mathrm{m} \leq 3$ ). $2^{\text {nd }}$ effect of coupling of charges due to environmental neighboring groups effects. $3^{\text {rd }}$ the six oxygen atoms are liable to replace each other throughout the lattice to compensate any lattice defects could break bonds (evidence is exchanging positions of triangle base with axial positions).

\section{Conclusions}

Advanced solution route was successfully applied to synthesize cobalt cyclophosphates at ambient temperature. The products were examined by both of XRD, IR. Structural investigations via XRD proved that the product obtained at $1100^{\circ} \mathrm{C}$ is the best and fine structure with monoclinic structure phase and belongs to $C 12 / C 1$ space group with lattice parameter $a=11.809(2), \quad b=8.293(1), c=9.923(2)$ A respectively. A visualized investigations confirmed structure validity and stability at temperature of sintering $\left(1100^{\circ} \mathrm{C}\right)$. Visualization studies indicated that variations of bond distances between $\mathrm{Co} 1, \mathrm{Co} 2, \mathrm{P} 1$ and $\mathrm{P} 2$ and different six oxygen atoms $(\mathrm{O} 1, \mathrm{O} 2, \mathrm{O} 3, \mathrm{O} 4, \mathrm{O} 5$ and O6) inside crystal lattice are responsible for increasing lattice flexibility factor (by controlling in shrinkage and expansion coefficient) and consequently increase its bonds stability to break.

\section{References}

[1] Jouini, A.; Ga^con, J. C.; Ferid, M.; Trabelsi-Ayadi, M. Optical properties of praseodymium concentrated phosphates. Opt. Mater. 2003, 24, p.175.

[2] Kitsugi, T.; Yamamuro, T.; Nakamura, T.; Oka, M. Transmission electron microscopy observations at the interface of bone and four types of calcium phosphate ceramics with different calcium/phosphorus molar ratios. Biomaterials 1995, 16, p.1101.

[3] Jian-Jiang, B.; Dong-Wan, K.; Kug Sun, H. Microwave dielectric properties of $\mathrm{Ca}_{2} \mathrm{P}_{2} \mathrm{O}_{7}$. J. Eur. Ceram. Soc. 2003, 23, p. 2589.

[4] Martinelli, J. R.; Sene, F. F.; Gomes, L. Synthesis and properties of niobium barium phosphate glasses. J. Non-Cryst. Solids 2000, 263, p.299.

[5] Parada, C.; Perles, J.; Saez-Puche, R.; Ruiz-Valero, C.; Snejko, N. Crystal growth, structure, and magnetic properties of a new polymorph of $\mathrm{Fe}_{2} \mathrm{P}_{2} \mathrm{O}_{7}$. Chem. Mater. 2003, 15, p. 3347.

[6] Antraptseva, N. M.; Shchegrov, L. N.; Ponomareva, I. G. Thermolysis features of Manganese (II) and zinc dihydrogenphosphate solid solution. Russ. J. Inorg. Chem.2006, 51, p. 1493.

[7] Trojan, M.; Brandova', D. A study of thermal preparation of c$\mathrm{Mn}_{2} \mathrm{P}_{4} \mathrm{O}_{12}$. J. Therm. Anal. Calorim.1985, 30, p.159.

[8] Trojan, M. Double tetrametaphosphates $\mathrm{Mn}_{2}-x \mathrm{Cax} \mathrm{P}_{4} \mathrm{O}_{12}$ as special pigments. Dyes Pigm.1990, 12, p.35.

[9] Trojan, M. Binary cyclotetraphosphates $\mathrm{Zn}_{2}-x \mathrm{Cax} \mathrm{P}_{4} \mathrm{O}_{12}$ as new special pigments. Dyes Pigm.1990, 13, p. 1.

[10] Trojan, M.; Sÿulcova', P.; Mos`ner, P. The synthesis of binary zinc-(II)-Nickel (II) cyclo-tetraphosphates as new special pigments. Dyes Pigm. 2000, 44, p. 161.

[11] Trojan, M. A study of the reactions during formation of c$\mathrm{Ni}_{2} \mathrm{P}_{4} \mathrm{O}_{12}$. Thermochim. Acta1990, 160, p. 361.

[12] Trojan, M.; Brandova', D. A study of the thermal preparation of c-Cd4/3Ca2/3P $\mathrm{P}_{4} \mathrm{O}_{12}$. Thermochim. Acta 1990,160 , p.349. 
[13] Trojan, M.; Sÿulcova', P. Binary Cu (II)-Mn (II) cyclotetraphosphates. Dyes Pigm. 2000, 47, p. 291.

[14] Trojan, M.; Brandova', D.; Paulik, F.; Arnold. M. Mechanism of the thermal dehydration of $\mathrm{Co} 1 / 2 \mathrm{Ca} 1 / 2\left(\mathrm{H}_{2} \mathrm{PO}_{4}\right)_{2} .2 \mathrm{H}_{2} \mathrm{O} . J$. Therm. Anal. Calorim.1990, 36, p.929.

[15] Trojan, M.; Brandova', D. Mechanism of dehydration of Zn0.5- Mg0.5 $\left(\mathrm{H}_{2} \mathrm{PO}_{4}\right)_{2}$ â2 $\mathrm{H}_{2} \mathrm{O}$. Thermochim. Acta1990, 159, p. 1.

[16] Brandova', D.; Trojan, M.; Arnold, M.; Paulik, F. Thermal study of decomposition of $\mathrm{Cu} 1 / 2 \mathrm{Mg} 1 / 2\left(\mathrm{H}_{2} \mathrm{PO}_{4}\right)_{2} \cdot 0.5 \mathrm{H}_{2} \mathrm{O}$. J. Therm. Anal. Calorim. 1990, 36, p. 677.

[17] V. Ramakrishnan, G. Aruldhas, Vibrational spectra of $\mathrm{Cu}$ (II) and Co (II) tetrametaphosphates, Infrared Phys. 25 (1985) pp. 665-670.

[18] E. J. Baran, R. C. Mercader, A. Massaferro, E. Kremer,

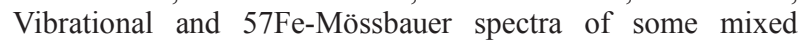
cationdiphosphates of the typeMIIFe2III $\quad\left(\mathrm{P}_{2} \mathrm{O}_{7}\right)_{2}$, Spectrochim. Acta. 60 (2004) pp. 1001-1005.

[19] E. H. Soumhi, I. Saadoune, A. Driss, A new organiccationcyclotetraphosphate $\mathrm{C}_{10} \mathrm{H}_{28} \mathrm{~N}_{4} \mathrm{P}_{4} \mathrm{O}_{12} \quad 4 \mathrm{H}_{2} \mathrm{O}$ : crystal structure, thermal analysis, and vibrational spectra, J. Solid State Chem. 156 (2001) pp. 364-369.

[20] Averbuch-Pouchot, M. T., Durif, A.: Crystal structure of lead tetrapolyphosphate: $\mathrm{Pb}_{3} \mathrm{P}_{4} \mathrm{O}_{13}$. Acta Crystallogr. C43 (1987) pp. 631-632.

[21] Chudinova, N. N., Lavrov, A. V., Tananaev, 1. V.: Reaction of bismuth oxide with phosphoric acid during heating. Izv. Akad. Nauk SSSR, Neorg. Mater. 8 (1972) pp.1971-1976.
[22] Durif, A., Averbuch-Pouchot, M. T., Guitel, J. c.: Structure cristalline de $\left(\mathrm{NH}_{4} \mathrm{hSiP}\right.$ 4013: unnouvelexemple de siliciumhexacoordine. Acta Crystallogr. B32 (1976) pp. 2957 $-2960$.

[23] Enraf-Nonius: Structure Determination Package. RSX 11M version. Enraf-Nonius, Delft (1977).

[24] Hilmer, N., Chudinova, N. N., Jost, K. H.: Condensed bismuth phosphates. Izv. Akad. Nauk SSSR, Neorg. Mat. 14 (1978) pp.1507-1515.

[25] International Tables for X-ray Crystallography (Present distributor D. Reidel, Dordrecht), Vol. IV, Birmingham: Kynoch Press (1974).

[26] Palkina, K., Jost, K. H.: Crystal structure of the polyphosphaleBiH (P03k Acta Crystallogr. 831 (1975) pp. $2285-2290$.

[27] Schulz, 1.: Uberzweikristalline Tetraphosphate. Z. Anorg. Allg.Chern. 287 (1956) pp. 106-112.

[28] Tezikova, L. A., Chudinova, N. N., Fedorov, P. M., Lavrov, A. V.: Bismuth acid pyrophosphate. Izv. Akad. Nauk SSSR, Neorg. Mat. 10 (1974) pp. 2057 -2063.

[29] KhaledM. Elsabawy, NaderH. Elbagoury, Structure Visualization and AFM-Surface Microstructural Investigations on Ni-Ti-O Mixed Oxide With $\mathrm{ABX}_{3}$-Structure of Cast NiSuperalloy, Adv. Appl. Science. Res., 2, 2 (2011) pp.38-47.

[30] Khaled M. Elsabawy, Structure Visualization, Mechanical Strength Promotion and Raman Spectra of Hafnium Doped 123-YBCO Superconductor synthesized via Urea Precursor Route, Cryogenics, 51 (2011) pp.452-459. 